\title{
Challenges Associated With The Construction And Operation Of Seasonal Storage For A Small Solar District Heating System: A Multi-Objective Optimization Approach
}

\author{
Mohamed Hany Abokersh \\ Departament d'Enginyeria \\ Mecànica \\ Universitat Rovira i Virgili \\ Av. Països Catalans 26, 43007 \\ Tarragona, Spain \\ Mohamed.Abokersh@urv.cat
}

\author{
Manel Vallès \\ Departament d'Enginyeria \\ Mecànica \\ Universitat Rovira $i$ Virgili \\ Av. Països Catalans 26, 43007 \\ Tarragona, Spain \\ Manel.Valles@urv.cat
}

\author{
Luisa F.Cabeza \\ GREiA Research Group, \\ INSPIRES Research Centre \\ Universitat de Lleida \\ Pere de Cabrera s/n, 25001 \\ Lleida, Spain \\ luisaf.cabeza@udl.cat
}

\author{
Dieter Boer \\ Departament d'Enginyeria \\ Mecànica \\ Universitat Rovira i Virgili \\ Av. Països Catalans 26, 43007 \\ Tarragona, Spain \\ Dieter.Boer@urv.cat
}

\begin{abstract}
Solar assisted district heating systems (SDHS) is a promising pathway towards sustainable transaction to clean energy production. However, the technical performance variation due to the misestimation of the seasonal storage tank (SST) combined with inadequate financial assessment and insufficient environmental impact data associated with the deployment of those innovative systems represents a big challenge for the broad implementation of SDHS in Europe. This paper evaluates the feasibility of deploying the SDHS at a small urban community sizes with tracing its techno-economic failures as well as its environmental impact. Furthermore, this study attempts to focus on the technical failure of the SST through including its geometry as well as its design parameters in the optimization framework. The capabilities of this approach are illustrated through a case study of a SDHS located in Madrid (Spain), to satify the heating demand for an urban community of 10 building with total heating demand of 1913.4 MWh/a. The optimization results show that including the SST geometry and its construction properties can effectectively enhance the SDHS feasibility, especially from the technical and environmental point of view.
\end{abstract}

Keywords-Solar district heating system, seasonal storage, Life cycle cost, Life cycle assessment, Multi-objective optimization

\section{INTRODUCTION}

There has to be a change toward sustainable energy scheme (e.g. electricity, heating) if the European Union is to meet its goal of preventing carbon dioxide $\left(\mathrm{CO}_{2}\right)$ emissions by up to $95 \%$ (in comparison to the values obtained in 1990) in 2050 (see the Energy Roadmap 2050 from the European Commission) [1]. The heat demand (e.g. domestic hot water and space heating) in the building industry contributes up to 40 $\%$ of the current emissions status, which is a great contribution to the decarbonization milestone of the European Union [2]. Currently, the heating and cooling sector in the building industry is going through various development so as to introduce more renewables. Later, this will in return allow for the substitution of the usual fossils (e.g. gas). At the moment, solar thermal systems are the most energy-effective in terms of renewable energy systems, and it can be expanded from residential applications (e.g. solar thermal panels) to be used in urban areas (solar district heating systems) [3].

However, there is a bit of a drawback when it comes to solar energy since there is always temporal fluctuation (daily and seasonal). Nevertheless, this type of issues can be seen in various other energy storage options like the thermal energy storage for heat-supply applications. Thermal energy storage (TES) is a major part of the solar thermal applications given that it contributes enormously, with the capability to enhance the efficiency and flexibility of solar systems. TES can store up excess energy for use later when energy is needed. Hence, TES is mostly used as a back-up equipment for district heating (DH) systems [4,5]. Along with a large-scale seasonal TES, solar district heating system (SDHS) is capable of handling the flexibility between the supply and demand of energy [6]. A good example of the SDHS system is the CrailsheimHirtenwiesen district heating in Germany. It comes with a seasonal thermal energy storage (STES) that is capable of taking a share of the renewables. In 2014, a $10000 \mathrm{~m}^{3}$ borehole for seasonal storage was built to increase the solar output by up to $20 \%$.

As a result, it is believed that a long-term and large-scale TES allows for a smoother and more flexible integration of solar energy in district heating systems. In terms of lower fossil fuels consumption, it is great benefit, as it has lower emissions and higher primary energy savings [6]. Apart from a few drawbacks, the developed SDHS has performed quite well and has been widely acceptable especially when considered as field trials of new designs. Even though some installations perform well, others do not. In some cases, the performances of the solar collector are overestimated, while the losses associated with the 


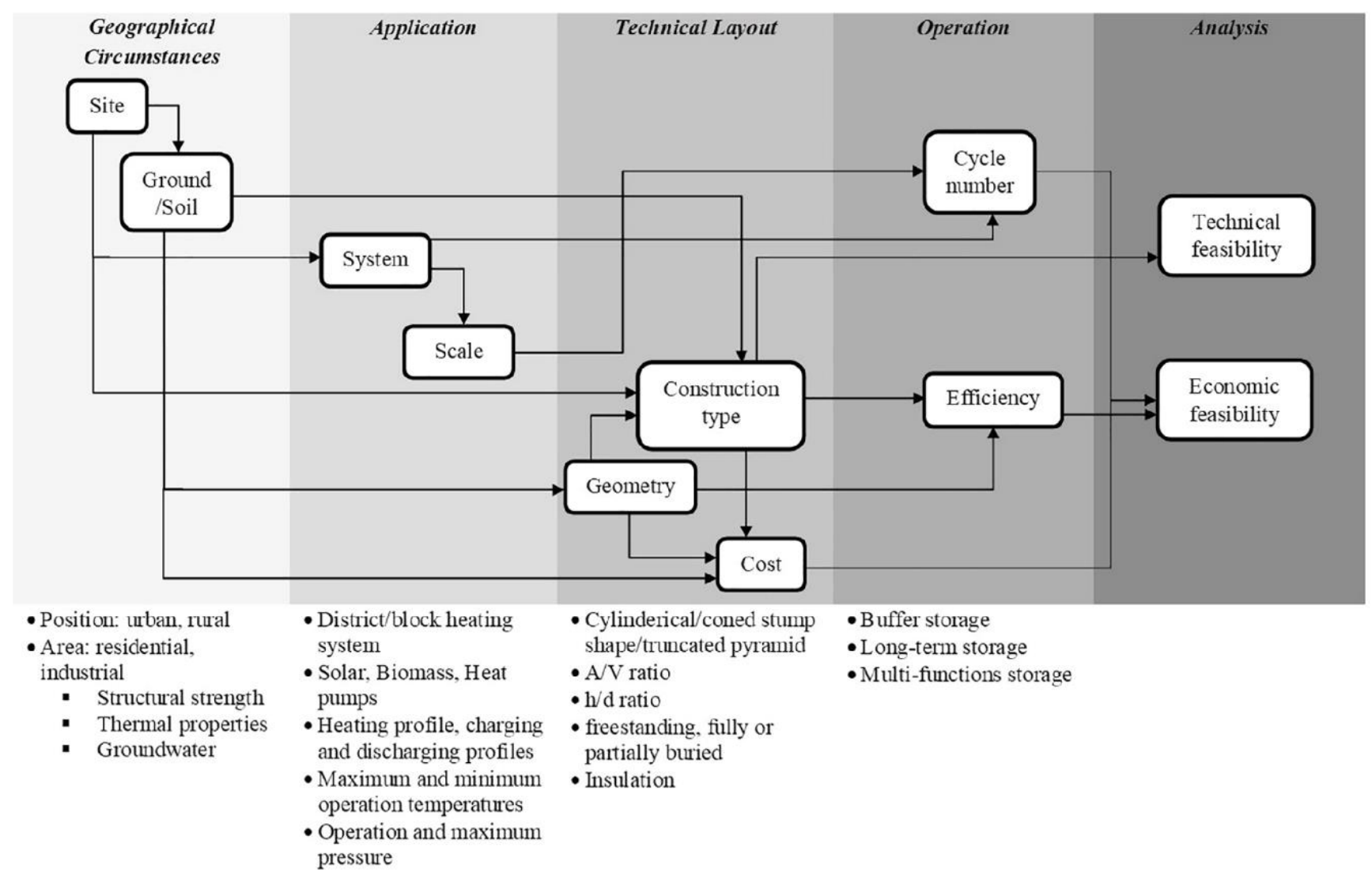

Fig. 1. Schematic representation of the parameters that mostly influence the construction of large-scale underground TES and its economic feasibility [6]

heat store are underestimated. There are a lot of reasons why this happens. One of the reasons is that the right tools for predesign studies were not utilized. Other reasons include using wrong inputs, wrongful application of the design tools, and optimization problems that have to do with cost and size.

Unsurprisingly, performance has not been at par given that the theoretical models used in pre-studies discuss performance under ideal conditions. Many operational challenges have to do with the wrong application of various technologies [7].

In Friedrichshafen, Germany, the performance of the solar fraction is estimated to reach up to $43 \%$. Nevertheless, under realistic operation setup, the monitoring data indicated that a solar fraction between $21 \%$ and $33 \%$ is attainable [8]. Higher solar fraction value has never been obtained as a result of many problems such as higher heating demand in comparison to expectation, increased thermal losses in the seasonal storage, and reduced heat exchanger and solar collector efficiencies [7]. Similar problem has been detected in other SDHS installed in Rockstock and Neckarsulm [9]. Besides, the installed plants in Hamburg, Steinfurt-Borghorst, and Neckarsulm II show a significant deviation between the monitored performance and design as a result of the high thermal losses in the seasonal as well as other tanks, smaller solar collector area than the planned, and high net return temperature [10]. The SDHS built in Crailsheim-Hirtenwiesen was meant to cover $50 \%$ of the heating needs of a residential area that has 260 apartments, a gym, and a school. To make sure that the system is accessible all year, a borehole that can store up to $10000 \mathrm{~m}^{3}$ per season was added to the system [11]. When the performance was monitored, there was a considerable difference between the real and estimated solar fraction by up to $60 \%$. This huge difference is as a result of the ground losses in addition to higher operating temperature in the space heating network [12]. The Drake Landing Solar Community in Canada is the most popular solar community. This system has been able to use solar energy to cover $98 \%$ of the space heating demand [13]. However, during five years of monitoring, a high-performance variation was noticed in this solar community. A report from ASHRAE [14] stated that the reason for the system underperformance in comparison to the simulation results is the high thermal losses all over the network, pump control, and the stratification of the storage tank . Apart from the abovementioned issues, Claudia Weissmann et al.[15] stated that the orientation of the building, the orientation of the thermal collector in addition to the pipe leakages could have an adverse effect on the performance of the SDHS.

Moreover, the high investment cost of STES is usually a major drawback. Also, issues with the availability of space, presence of groundwater tables, and complex planning layout are the main challenges that should be dealt with in STES, among others [16]. To increase the advantages of a seasonal 
TES, the optimal size and design of STES as well as the appropriate components (e.g. discharging/charging devices) should be well planned. To a great extent, planning and the building of large-scale seasonal TES is a complicated process. Dahash et al. [6] showed the large number of inputs that should be considered in the whole project planning process. In the section that follows, the problems in the planning stage are discussed thoroughly as shown in Fig. 1.

\section{SYSTEM DEVELOPMENT AND SIMULATION}

\section{A. System development}

The study is carried out for a virtual residential community with an exclusive assisted solar district network. Introduced earlier, TRNSYS 18 is the dynamic simulation software in which SDHS was modeled [17]. The system has three key parts: DHW circuits, space heating, and solar field loop. The heat exchangers $(1 \& 2)$ are connected to the solar field (primary loop), then to the space heating and finally to the DHW circuits (secondary circuits) as shown in Fig.2. The primer utilizes a water-glycol mixture (67/33 weight) as heat transfer fluid so as to protect the solar field from freezing in winter nights. After the solar collectors have harvested energy, it is transferred to either the DHW storage (preferably to this one) or to the seasonal energy storage. Built of reinforced concrete, the seasonal storage tank has a cylindrical shape and is used for storing water. Through a third heat exchanger, it is linked to the distribution system (3) that preheats the water that returned from the heating network. Given its huge size, the processes of unloading and loading the seasonal storage tank are very slow, which assists in taking care of the space heating demand during winter with the solar thermal energy stored in the summer season. The seasonal storage tank is much bigger than the DHW storage, which is an independent tank. It is used to get a few hours of solar energy reaching the required temperature of $60^{\circ} \mathrm{C}$ for the daily service of the DHW. Due to its design, in addition to the priority of loading the DHW tank with respect to the seasonal storage tank, the DHW can get high solar fractions. For a low-temperature district heating network, the space heating system makes hot water at $50^{\circ} \mathrm{C}$.

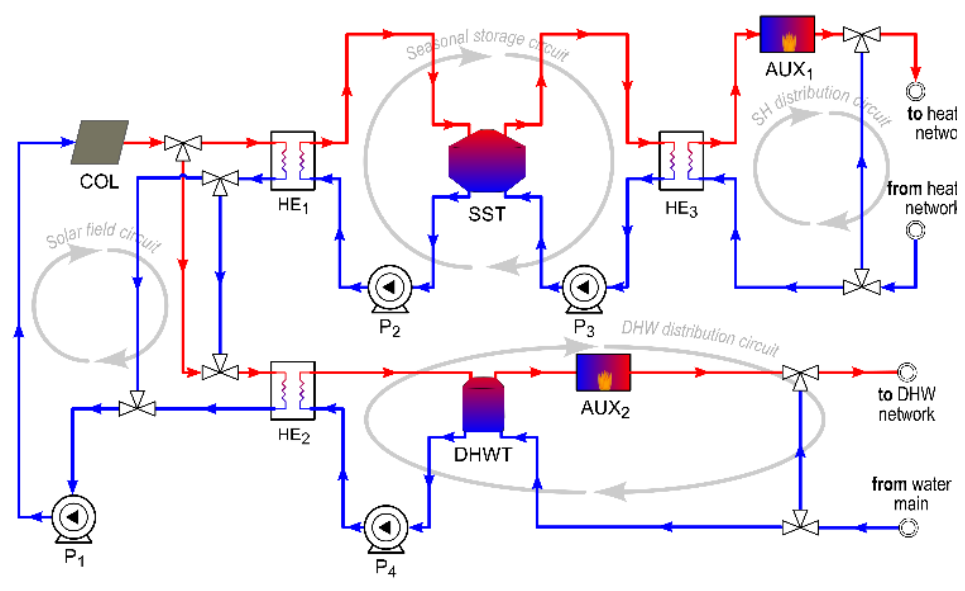

Fig. 2. Simple schematic representation for the SDHS [17]

This project has received funding from the European Union's Horizon 2020 research and innovation programme under the Marie Skłodowska-Curie grant agreement No. 713679 and from the Universitat Rovira i Virgili (URV).
A transient simulation software, TRANSYS 18, is used to assess the proposed SDHS' dynamic behavior. The program's dynamic nature is able to provide a real simulation of the SDHS plant. The developed simulation model is similar to the models developed by Tulus et al. [18] and Guadalfajara et al. [19], with a few changes such as the DHW distribution network.

To ensure that SDHS components are integrated in TRNSYS, they come in the form of blocks that are linked together as shown in Fig.3 . Every component has three information boxes, which are the input variables, componentspecific parameters, and output variables. Due to its small computing power, the problem solution is gotten in usually over one year of operation, and the solution is made to extend over the lifetime of the plant.

There are several components in the TRNSYS simulation model such as: (1) Type 1 flat plate solar collectors that have an optical efficiency of 0.817 , (2) sensible storage tanks (Type 4) heat loss coefficient of $0.06 \mathrm{~W} / \mathrm{m}^{2} . \mathrm{K}$ and $0.3125 \mathrm{~W} / \mathrm{m}^{2} . \mathrm{K}$ for the seasonal and DHW tanks, respectively and fixed inlets, counter flow heat exchangers (Type 5) with total heat transfer coefficient of $3931 \mathrm{~W} / \mathrm{m}^{2} . \mathrm{K}$, and auxiliary heaters (Type 5) that have an efficiency of $93 \%$. Other components are outlet and inlet pipe ducts (Type 31), single-speed circulation pumps (Type 3d), the ground conditions for the seasonal storage tank (Type 77), three-way valves (Type 11), time-dependent forcing function for the heating and DHW demand (Type 9), and TMY2 files for the meteorological data (Type 15).

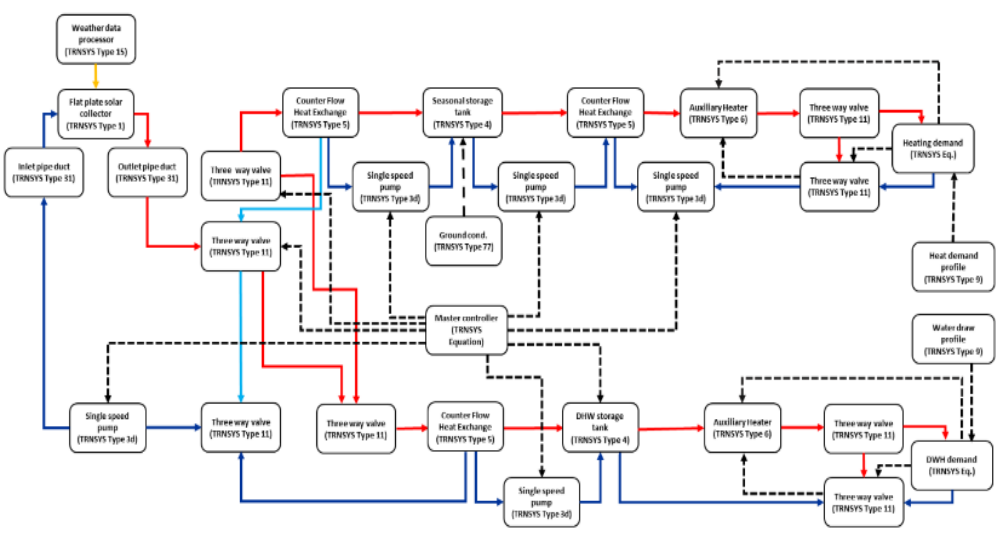

Fig. 3. The information flow diagram for TRNSYS model [17]

\section{EVALUATION CRITERIA}

\section{A. Technical criteria}

Many parameters such as the domestic hot water storage tank (DHWT), energy supplied by the seasonal storage tanks (SST), and auxiliary boilers are used to technically evaluate the dynamic behavior of the SDHS plant.

The storage tank plays an important role in the performance of the SDHS plant. Eq (1) and (2) describe the energy supplied by the fully stratified DHW and seasonal storage tanks [20]. 


$$
\begin{aligned}
& \dot{Q}_{\text {Seasonal tank }}=\dot{m}_{f} c_{p}\left(T_{\text {out, Seasonal tank }}\right. \\
& \left.\quad-T_{\text {return,building }}\right) \\
& \dot{Q}_{D H W \text { tank }}=\dot{m}_{D H W} c_{p, w}\left(T_{\text {out }, D H W \text { tank }}-T_{\text {in,cold }}\right)
\end{aligned}
$$

Thermal heat loss is another feature of the SST performance. This can be assessed via heat losses through the bottom, sides, and top of the storage. The heat loss via these surfaces is dependent on the type of material used for construction, the ground properties, the insulation material and the height to diameter ratio. through its heat loss coefficient, many simple equations can be used to represent the SST thermal heat loss $\left(Q_{S S T \text { loss }}\right)$ given the SST design guide recommended by M. Chung et al.[21] as shown in Eqs. (3) to (6).

$$
\begin{aligned}
& Q_{\text {SST loss }}=A_{\text {Roof }} U_{\text {Roof }}+A_{\text {Wall }} U_{\text {Wall }}+A_{\text {Gnd }} U_{\text {Gnd }} \\
& U_{\text {Roof }}=\frac{1}{\frac{d_{\text {con }}}{\lambda_{\text {con }}}+\frac{d_{\text {Roof }}}{\lambda_{\text {ins }}}+\frac{1}{h_{\text {conv }}}} \\
& U_{\text {Wall }}=\frac{1}{\frac{d_{\text {con }}}{\lambda_{\text {con }}}+\frac{d_{\text {Wall }}}{\lambda_{\text {ins }}}+\frac{1}{h_{\text {conv }}}} \\
& U_{\text {Gnd }}=\frac{2}{R^{2}\left\{a\left(\frac{\lambda_{\text {Gnd }}}{\pi}\right)^{2} \cdot \ln \left[\frac{a}{\pi-\left(\frac{\pi R}{\lambda_{\text {Gnd }}}\right)}\right]-\frac{R \cdot \lambda_{\text {Gnd }}}{\pi}\right.} \\
& \left.\quad+\frac{1}{h_{\text {conv }}}\right\}
\end{aligned}
$$

Where: $\quad a=\frac{\pi R}{\lambda_{\text {Gnd }}}+\frac{\left(d_{\text {con }}+d_{\text {Gnd }}\right)}{\lambda_{\text {Gnd }}}+\frac{d_{\text {con }}}{\lambda_{\text {con }}}+\frac{d_{\text {Gnd }}}{\lambda_{\text {Gnd }}}$

Where $A_{\text {Roof }}, A_{\text {Wall }}$, and $\mathrm{A}_{\mathrm{Gnd}}$ are the surface areas of the top, wall, and bottom SST, respectively. While $U_{R o o f}, U_{W a l l}$, and $U_{G n d}$ represent their relative heat loss coefficient, respectively. $\mathrm{R}$ is the SST radius, $d_{\text {con }}$ represents the thickness of the construction material, whereas $d_{\text {Roof }}, d_{\text {Wall }}$ and $d_{\text {Gnd }}$ represent the top, wall, and bottom surfaces insulation thicknesses of the SST, respectively. Moreover $\lambda_{\text {con }}$ represents the construction material's thermal conductivity, whereas $\lambda_{\text {Roof }}, \lambda_{\text {Wall }}$, and $\lambda_{\text {Gnd }}$ represent the thermal conductivity of the insulation material for the roof, wall, and bottom surfaces of the SST, respectively.

The auxiliary boilers are used to meet the DHW and heat demand whenever the solar system cannot reach a given temperature point. Eq. (7) below is the expression for the auxiliary energy rate supplied to the system [22].

$$
\dot{Q}_{A U X}=\dot{m} c_{p} \cdot \Delta T_{L}
$$

Where $\Delta T_{L}$ is the difference in temperature between the demand and the temperature provided by the solar loop.

A set of nominal performance parameters are used to assess the technical performance of the solar field circuit, as well as the DHW and SH distribution circuits. These parameter include SST, the solar collector, the efficiencies of the DHWT [23,24], and the yearly solar fraction for both the DHW and SH distribution circuits $[25,26]$. To calculate these performance indicators, equations ( 8 to 12 ) are used as a function of the energy flow over the distribution circuits and the solar field.

$$
\begin{aligned}
& \eta_{C O L}=\frac{\int_{0}^{t} \dot{Q}_{\text {Useful }}}{\int_{0}^{t} \dot{Q}_{S O L}} \\
& \eta_{S S T}=1-\frac{\int_{0}^{t} \dot{Q}_{S S T \text { loss }}}{\int_{0}^{t} \dot{Q}_{H E_{1}}} \\
& \eta_{D H W T}=1-\frac{\int_{0}^{t} \dot{Q}_{D H W \text { loss }}}{\int_{0}^{t} \dot{Q}_{H E_{3}}} \\
& S . F_{S H}=1-\frac{\int_{0}^{t} \dot{Q}_{A U X_{1}}}{Q_{S H \text { load }}} \\
& S . F_{D H W}=1-\frac{\int_{0}^{t} \dot{Q}_{A U X_{2}}}{Q_{D H W \text { load }}}
\end{aligned}
$$

Where $\dot{Q}_{U s e f u l}$ and $\dot{Q}_{S O L}$ are the useful energy produced and received by the solar collector field, respectively. $\dot{Q}_{S S T}$ loss and $\dot{Q}_{D H W}$ loss represent the heat loss in the SST and DHWT, whereas the $\dot{Q}_{H E_{1}}$ and $\dot{Q}_{H E_{3}}$ are the heat transfer rate via the heat exchangers, $\mathrm{HE}_{1}$ and $\mathrm{HE}_{3}$. Moreover, $\dot{Q}_{A U X_{1}}$ and $\dot{Q}_{A U X_{2}}$ states for the auxiliary energy rate supplied by the natural gas boilers in the SH and DHW distribution circuits to cover the $\mathrm{SH}$ load $\left(Q_{S H \text { load }}\right)$ and DHW load $\left(Q_{D H W \text { load }}\right)$ demand when the solar system could not reach a specified temperature point.

\section{Economic criteria}

In this present study, the economic evaluation is in line with Tulus et al.[18] work, which was done based on the (LCC) methodology [20,27] for assessing how an SDHS plant performs financially.

The life-cycle cost analysis is a valuable monetary method of evaluating the designs of energy systems in terms of the initial purchase cost taking into account the operation of the system throughout its lifetime. The LCC approach in the early phase of design allows the decision makers to fully understand the system cost throughout its lifetime [28], and afterwards see 
if they can reduce the operational cost of the system even if more investment is needed [29].

The LCC methodology mainly looks at the future cost. The major thing about this approach is that it tries to discount the overall expenses during system's lifetime to its current value where the net present cost $(N P C)$ is calculated by adding the total replacement of the equipment $\left(C_{R}\right)$, the operational cost $\left(C_{O}\right)$, and the initial purchase $\operatorname{cost}\left(C_{I}\right)$.

$$
N P C=C_{I}+C_{O}+C_{R}
$$

\section{Environmental criteria}

Apart from the LCC methodology for evaluating how the SDHS performs economically, the environmental impact of the system is appraised using a life cycle assessment approach (LCA) [30]. This approach gives a full analysis of the system components at the production stage, including their operation and disposal based on the "cradle to grave" approach [31]. The LCA as standardized in the ISO 14040 series [32-34] and consists of many phases that trail a certain sequence; the goal and the scope definition, impact assessment, and Life cycle inventory.

The LCA carried out in this study recommends the scope and goal stage for establishing system boundary and its functional unit. In this situation, the definition of the functional unit is the yearly heating demand for the DHW and SH over the system's lifetime. The boundary for the SDHS is drawn based on the "cradle to gate" approach given that this study focuses on the already existing district heating, with the exception of the disposal stage (end of life). This is common in the LCA approach given that the disposal phase is insignificant compared to the use and production phases. Besides, the recycling phase is negligible too due to its difficulty in prediction and advance [35].

Based on various databases, this stage compiles the material output, input, and their relative energy consumption during the operation and building of the plant. This present study assesses the impact of manufacturing equipment and utility energy consumption (natural gas by electricity) by the SDHS throughout the lifetime of the system. In addition, the impact of transporting materials and plant components to the site during its operation are evaluated. These impact data are fetched from the Ecoinvent 3.5 database [36].

Subsequently, the inventory data are weighted and arranged into impact categories. These damages consist of human health problems, resources damage, and damage to ecological system. In this study, the ReCiPe 2016 framework is recommended for the assessment of various environmental categories based on the aggregated endpoint indicator metric $(R C P)$ instead of using the mid-point indicators that could misinterpret the overall environmental performance of the SDHS with different sized systems. The RCP can be expressed as follows:

$$
R C P=\sum_{d} \delta_{d} \varepsilon_{f} D A M_{d} \quad \forall d
$$

Where $D A M_{d}$ represents the endpoint of the damage category $d$, and $\delta_{d}, \varepsilon_{d}$ are the specific normalization and weighting factors. The normalized factors are clearly stipulated based on the damage to the European land uses and their relative material extractions [37]. Contrarily, the weighting factors are calculated based on the ReCiPe 2016 system [17].

\section{OPTIMIZATION METHODOLOGY}

\section{A. Problem definition}

The aim of this paper is to identify the technical failure of the SDHS in small urban city. Its decision variables are expanded by presenting the construction design parameters and SST geometry in an optimization framework. Thus, the energy performance is optimized along with the environmental and economic system needs using the MOO framework to tackle the multi-objective conflict.

\section{B. Objective functions}

This study sets the environmental and economic benefits of SDHS as objective functions to be reduced. These parameters are used primarily due to the high operational (and environmental problems in general) and initial costs, which are of interest to the end user while the contractor is interested in the investment cost. Additionally, majority of the companies that build these systems are more interested in the system's investment cost and the environmental effect. Thus, it is critical to assess all these quantities so as to evaluate the overall system performance. The two analyzed functions include the environmental impact $(R C P)$ and the total economic cost $(N P C)$ of the system. This is expressed as:

$$
\begin{aligned}
& \min \left\{f_{1}(x), f_{2}(x)\right\} \\
& \text { s.t. } h(x)=0 \\
& \quad g(x) \geq 0 \\
& l b_{i} \leq x_{i} \leq u b_{i} \quad i \in\{1, \ldots, 15\}
\end{aligned}
$$

where ' $x$ ' is the vector of the design variables as stipulated in the section below. There are 15 decision variables in this problem; these decision variables explain the different components in the SDHS, such as its size and the relative construction and orientation. These variables are classified depending on the circuit name. In the solar field circuit, (i) COL inclination angle $\left(\beta_{\mathrm{COL}}\right)$, (ii) $\mathrm{COL}$ area $\left(\mathrm{A}_{\mathrm{COL}}\right)$, and (iii) number of COL in series $\left(\mathrm{N}_{\mathrm{COL}}\right)$ are taken into account. In the $\mathrm{SH}$ distribution circuit, (i) SST volume ( $\mathrm{V}_{\mathrm{SST}}$ ), (ii) SST aspect ratio (HDR), (iii) SST construction material $\left(\lambda_{\text {con }}\right)$ including (NC: Normal concrete, HPC: High performance concrete, and UHPC: Ultra high performance concrete, (iv) SST roof, wall, and ground insulation material type $\left(\lambda_{\text {ins }}\right),(v)$ ground insulation material type $\left(\lambda_{\text {ins gnd }}\right)$ including (XPS: Extruded polystyrene insulation, MW: Mineral wool, and FG: Fiberglass), (vi) roof, wall, and ground insulation material thickness ( $\left.\mathrm{T}_{\mathrm{Roof}}\right),\left(\mathrm{T}_{\text {Wall }}\right)$, and $\left(\mathrm{T}_{\mathrm{Gnd}}\right)$, respectively, and (vii) $\mathrm{AUX}$ fraction $\left(\mathrm{FC}_{\mathrm{AUX1}}\right)$ are 
taken into consideration. Lastly, in the DHW distribution circuit, (i) DHWT volume $\left(\mathrm{V}_{\mathrm{DHWT}}\right)$, (ii) DHWT aspect ratio ( $\left.\mathrm{HDR}_{\mathrm{DHW}}\right)$, and (iii) $\mathrm{AUX}_{2}$ fraction $\left(\mathrm{FC}_{\mathrm{AUX} 2}\right)$ are taken into account. A broad range of decision variables is assessed for optimization and simulation processes based on real executed projects in EU and recommendation for numerous articles, as shown in Table I. Contrarily, how other equipment units are sized in the SDHS is decided via mathematical equations that link them to decision variables.

TABLE I. DECISION VARIABLES FOR THE SDHS CLASSIFIED BY CIRCUIT NAME

\begin{tabular}{|c|c|c|c|c|}
\hline $\begin{array}{l}\text { Circuit } \\
\text { name }\end{array}$ & $\begin{array}{l}\begin{array}{l}\text { Decision } \\
\text { variable }\end{array} \\
\end{array}$ & Unit & Uniform & Discrete \\
\hline \multirow{3}{*}{$\begin{array}{l}\text { Solar field } \\
\text { circuit }\end{array}$} & $\mathrm{A}_{\mathrm{COL}}$ & $\mathrm{m}^{2} / \mathrm{MWh} / \mathrm{a}$ & $0.1: 2$ & \\
\hline & $\beta_{\mathrm{COL}}$ & o & $20: 70$ & \\
\hline & $\mathrm{N}_{\mathrm{COL}}$ & - & $1: 10$ & \\
\hline \multirow{15}{*}{$\begin{array}{c}\mathrm{SH} \\
\text { distribution } \\
\text { circuit }\end{array}$} & $\mathrm{V}_{\text {SST }}$ & $\mathrm{m}^{3} / \mathrm{MWh} / \mathrm{a}$ & $1: 20$ & \\
\hline & HDR & $\mathrm{m} / \mathrm{m}$ & $0.3: 1.5$ & \\
\hline & $\mathrm{d}_{\text {Roof }}$ & $\mathrm{m}$ & $0.2: 0.7$ & \\
\hline & $\mathrm{d}_{\text {Wall }}$ & $\mathrm{m}$ & $0.2: 0.7$ & \\
\hline & $\mathrm{d}_{\text {Gnd }}$ & $M$ & $0.2: 0.7$ & \\
\hline & $\lambda_{\text {con }}$ & W/m. K & - & $\begin{array}{c}N C=1.5 \\
\mathrm{w} / \mathrm{m} . \mathrm{k}\end{array}$ \\
\hline & & & & $\begin{array}{c}H P C=2.5 \\
\mathrm{w} / \mathrm{m} . \mathrm{k}\end{array}$ \\
\hline & & & & $\begin{array}{c}U H P C=1.6 \\
\mathrm{w} / \mathrm{m} . \mathrm{k}\end{array}$ \\
\hline & $\lambda_{\text {ins }}$ & W/m. K & - & $\begin{array}{c}X P S=0.032 \\
\text { w/m. k }\end{array}$ \\
\hline & & & & $\begin{array}{c}M W=0.04 \\
\text { w/m. k }\end{array}$ \\
\hline & & & & $\begin{array}{c}F G=0.06 \\
\text { w/m. k }\end{array}$ \\
\hline & $\lambda_{\text {ins gnd }}$ & W/m. K & - & $\begin{array}{c}X P S=0.032 \\
\mathrm{w} / \mathrm{m} . \mathrm{k}\end{array}$ \\
\hline & & & & $\begin{array}{c}M W=0.04 \\
\text { w/m. k }\end{array}$ \\
\hline & & & & $\begin{array}{c}F G=0.06 \\
\text { w/m. k }\end{array}$ \\
\hline & $\mathrm{FC}_{\mathrm{AUX1}}$ & - & $0.1: 1$ & \\
\hline \multirow{3}{*}{$\begin{array}{c}\text { DHW } \\
\text { distribution } \\
\text { circuit }\end{array}$} & $\mathrm{V}_{\text {DHWT }}$ & $\mathrm{m}^{3} / \mathrm{MWh} / \mathrm{a}$ & $0.05: 0.25$ & \\
\hline & $\mathrm{HDR}_{\mathrm{DHWT}}$ & $\mathrm{m} / \mathrm{m}$ & $1: 2$ & \\
\hline & $\mathrm{FC}_{\mathrm{AUX} 2}$ & $\%$ & $0.1: 1$ & \\
\hline
\end{tabular}

\section{Objective functions}

This study uses the Multi-Objective Genetic Algorithm (MOGA) since it can be linked very easily to a TRNSYS simulation. The MOGA can simultaneously handle a set of point, which would allow the user to acquire many Pareto frontiers in one go [38]. An elitist genetic algorithm (a variation of NSGA-II [39]) is proposed. This algorithm can work on a multi-objective problem simultaneously. Besides, it can manage continuous and discrete variables, in addition to inequality and equality constraints [40]. The evolutionary methodology is used to iteratively modify the solutions based on the internal ranking of each population. The crossover and mutation functions are used to generate these populations [38].
An automated simulation-based optimization model is obtained by merging the generated robust metamodel based on ANN and the NSGA-II algorithm. Based on Alajmi et al. [41] recommendation, the MOGA uses the NSGA-II algorithm with 1000 preliminary population due for 300 generations.

\section{CAse Study}

The methodology strategy is carried out on small urbansized community with the aim of handling all technical barriers with respect to the optimal deployment and modeling of SDHS. In combination with the legal and economic barriers, these barriers promote a high variation in measuring the advantages of SDHS throughout its lifetime.

The heating need of a small-sized neighborhood (10 buildings) has been met by an SDHS in Madrid (Spain). Each building has 28 apartments with 90 square meter of functional area [43] per apartment and furnished with a domestic hot water system and a radiant underfloor heating system so as to meet the DHW and $\mathrm{SH}$ demand at $60^{\circ} \mathrm{C}$ and $50^{\circ} \mathrm{C}$, respectively. The comparison of the SDHS heating demand and model validation was carried out in comparison to Guadalfajara et al. [44] and Tulus et al. [18]. For the purposes of comparison, a base case utilizing just natural gas boiler is taken into account. This conventional system can independently fulfill the DHW and SH demand from the SDHS.

\section{RESULTS AND DISCUSSION}

\section{A. Optimization results}

This stage involves the testing of the capability of the framework developed via the Madrid case study in a smallsized community off 10 buildings where the design variables of SST are taken into account while formulating the optimization problem so as to examine the effect of SST geometry and how it is constructed to improve the SDHS optimal solutions. Generally, the optimization results are presented in five scenarios, which are:

- Scenario 1: No environmental damage limits (Min. cost).

- Scenario 2 to $4: 25 \%, 50 \%$, and $75 \%$ damage reduction against the $1^{\text {st }}$ scenario, respectively.

- Scenario 5: $100 \%$ of the environmental damage limits (Min. impact).

Fig. 2 represents the optimal system cost with regard to NPC and its impact on the environment with regard to RCP under different scenarios. Even though the base case correlates with the conventional system, a clear tradeoff between the advocated objective functions is clearly stated in the movement from scenario 1 to 5 , where the overall cost rises while reducing the impact on the environment. If the base case (Natural gas boiler) is replaced with SDHS, this can greatly reduce the impact on the environment by $77.9 \%$ in scenario 1 (Min. cost) and $81.1 \%$, $83.5 \%, 85.7 \%$, and $87.1 \%$ for scenarios 2 to 5 using the latter value, which is a great improvement of the environmental impact. In contrast, the Pareto optimal solutions in small-sized 
city (10 buildings) weren't able to offer a marginal economic benefit given that just scenario 1 reduces the economic cost by $24.9 \%$, whereas there is an increase in economic cost by $11.1 \%$, $35.4 \%, 54.2 \%$ and $61.5 \%$ for scenarios 2 to 5 , respectively.

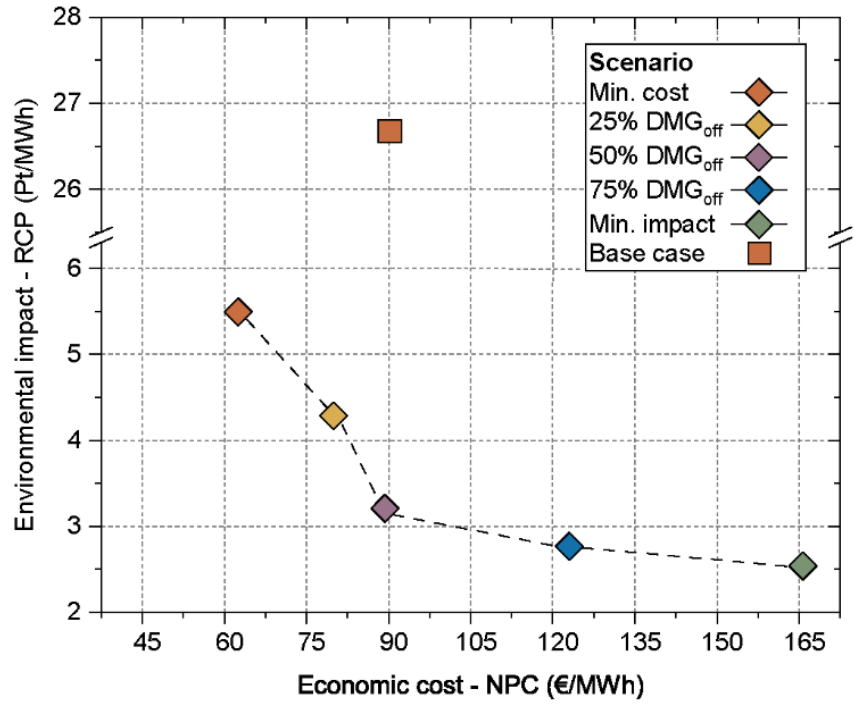

Fig. 2. Pareto sets for optimal SDHS solutions. These solutions meet the DHW and SH demand of 10 buildings located in Madrid at various scenarios compared to a conventical solution

Subsequently, each Pareto optimal solution is a representation of a specific configuration for the SDHS to meet the DHW and SH demand of a small urban city (10 buildings) situated in Madrid. The selected feature for every decision variable from scenario 1 to 5 is shown in Fig. 3. In the different optimization settings, an increase in the damage limitations would result in an increment in the share of renewable energy equipment. Adding the SST design variables in the optimization problem provides various configurations for SDHS, where the share of the solar collector rises only from $0.42 \mathrm{~m}^{2} / \mathrm{MWh} / \mathrm{a}$ at scenario 1 to $1.16 \mathrm{~m}^{2} / \mathrm{MWh} / \mathrm{a}$ at scenario 5 , whereas the share of the SST volume rises from $2.63 \mathrm{~m}^{3} / \mathrm{MWh} / \mathrm{a}$ at scenario 1 to 13.7 $\mathrm{m}^{3} / \mathrm{MWh} / \mathrm{a}$ at scenario 5 . Following the construction of the SST, the UHPC is superior to other construction materials in all scenarios. In addition, the insulation material used for all SST surfaces is foam glass gravel, excluding the min impact solution, which utilizes mineral wool as a result of its lower environmental impact. With regard to insulation thickness, all Pareto optimal solutions have wall insulation thicknesses ranging from 0.3 to 0.55 at all scenarios. In terms of the SST geometry, the HDR range from 0.63 to 0.77 . Additionally, the DHWT volume is relatively constant for the recommended settings, where its volume ranges from 0.08 to $0.15 \mathrm{~m}^{3} / \mathrm{MWh} / \mathrm{a}$.

The proposed framework aligns with the aim of handling the techno-economic performance of the SDHS, taking into account its environmental impact and provides a comprehensive analysis for the Pareto optimal solutions. Here, we evaluate the five optimal scenarios for the small-sized community from the environmental and economic standpoints.

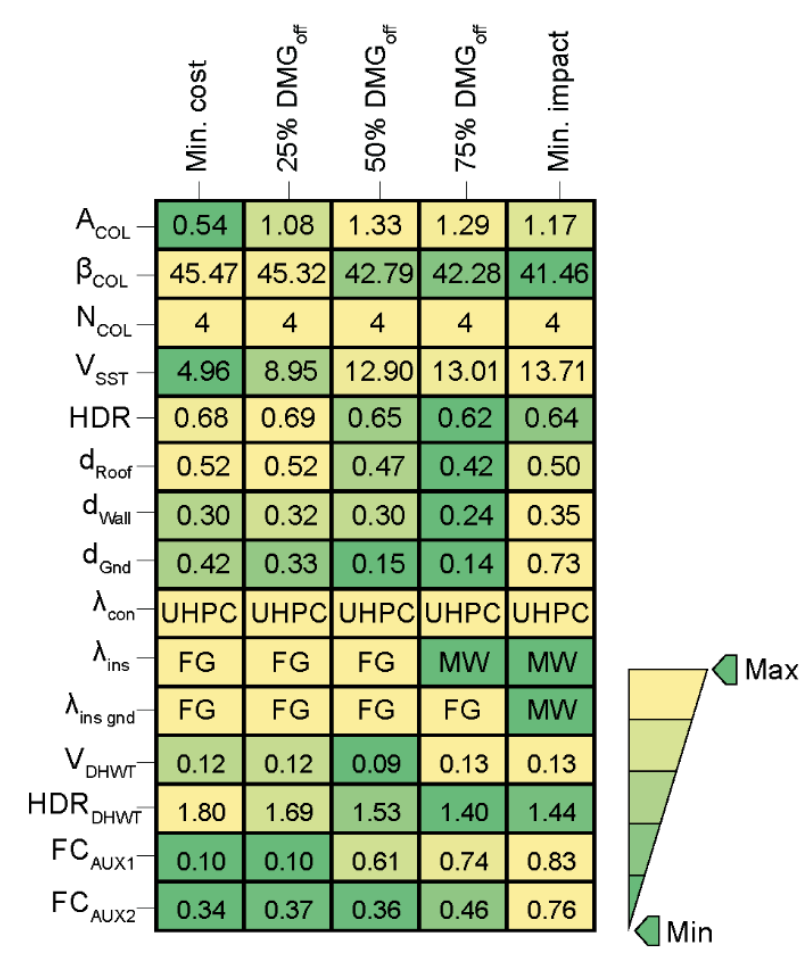

Fig. 3. SDHS configuration at different optimization scenarios

\section{B. Economic analysis}

To accelerate a comprehensive economic analysis of the SDHS, Fig. 4 shows a full breakdown of what each equipment costs in the SDHS throughout the lifetime of its operation in conjunction with the base case solution. From the figure, it can be seen that the initial capital contribution of the SDHS is so high compared to the base case solution. This expansion is as a result of the utilization of solar energy equipment in the heating system of the district, which implies high investment cost. More specifically, heat exchangers, the solar collectors, and SST greatly contribute to the initial capital cost. Adding the SST construction materials in the optimization framework can reduce the initial investment cost, where the SST contributes only $16.67 \%$ in scenario 1 (Min. cost) and reaches $43.7 \%$ in scenario 5 (Min. impact). An important contribution is considered in the replacement cost as a result of the solar energy equipment when compared to the base case solution. Contrarily, the operational cost contributes mostly $98.2 \%$ in the base case solution as a result of the use of natural gas. These are reduced contributions in SDHS, where the operational cost in scenario 1 is about $43 \%$. When the environmental damage limits increase (scenario 2 to 5), a reduced contribution to the operational expenses is observed for both optimization settings, where the cost of operation in scenario 5 is just about $24 \%$ as a result of the reduction in the use of Natural gas. This reduction is evident in the impact of SDHS optimal solutions on the environment. 


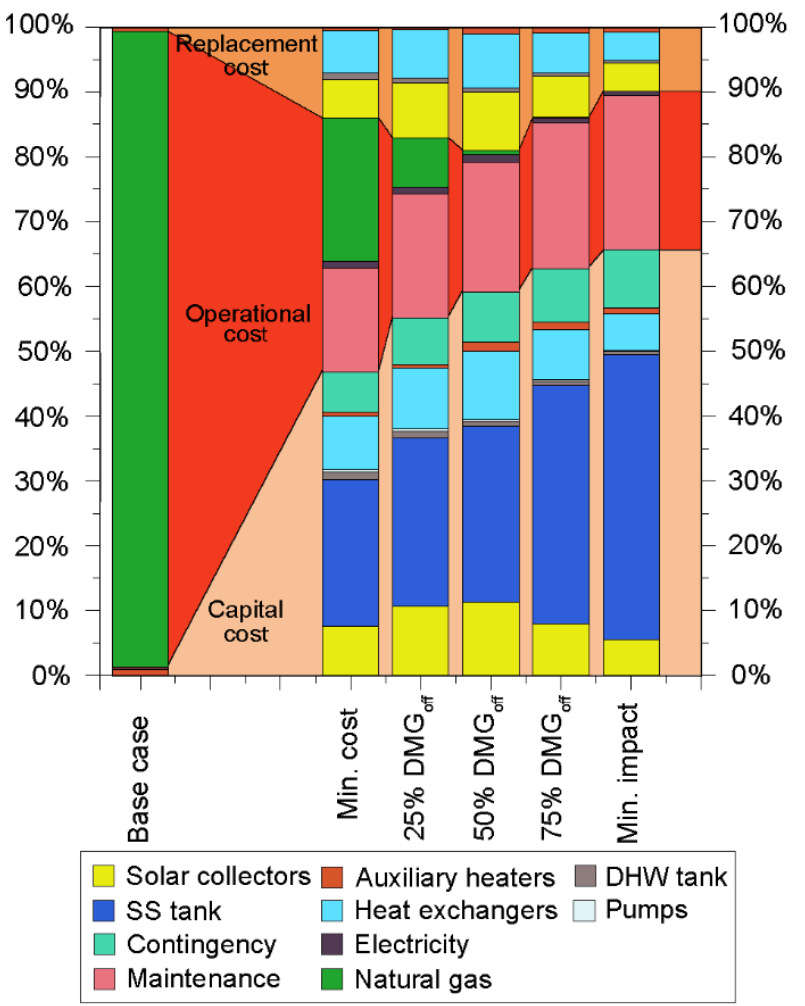

Fig. 4. A breakdown for the NPC including the shares of initial capital cost, operational cost, and replacement cost for Pareto optimal solutions at 5 optimal scenarios in comparison to its relative base case

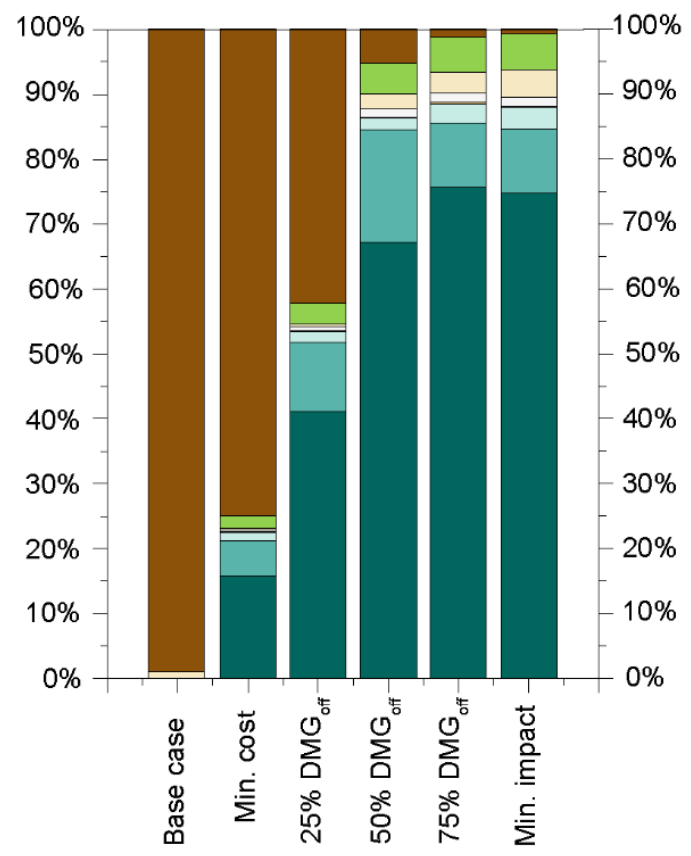

Solar collectors $\square$ Auxiliary heaters $\square$ DHW tank $\square$ SS tank $\quad \square$ Heat exchangers $\square$ Electricity

Natural gas

Fig. 5. A breakdown for the Breakdown of the RCP for Pareto optimal solutions at 5 optimal scenarios in comparison to its relative base case

\section{Environmental analysis}

Apart from the economic analysis, Fig. 5 also provides a comprehensive analysis for each equipment in the SDHS based on the aggregated ReCiPe 2016 when compared to the base case using natural gas. This figure shows that the consumption of natural gas in the base case is a representation of almost $100 \%$ of the overall impact. The SDHS optimal Pareto solutions can minimize the impact on the environment by up to $90.1 \%$. The system greatly depends on natural gas in Scenario 1, which correlates with $80.9 \%$ of the environmental impact. The impact by natural gas from scenario 2 to 5 steadily reduces with the increase in the environmental limits. In addition to the decrease in the natural gas impact share, a steady rise is evident in the impact of renewable energy, where the SST and solar collectors share most of the contribution to the overall environmental impact.

\section{Technical performance}

As can be seen in Fig.8, the evaluation of the thermal performance of the proposed SDHS is carried out by combining nominal performance indicators; these indicators consist of the key renewable energy equipment efficiencies and their corresponding solar fractions. A slight change in the $\eta_{C O L}$ is observed with the change in scenarios, where the highest $\eta_{C O L}$ is observed in scenario 1 as a result of the limited use of solar collector. Besides, the DHWT is used on a daily basis without storage; hence, a slight heat loss to the environment is evident in all scenarios. This is seen in the DHWT efficiency, where $\eta_{D H W T}$ could reach up to $96 \%$ for all scenarios.

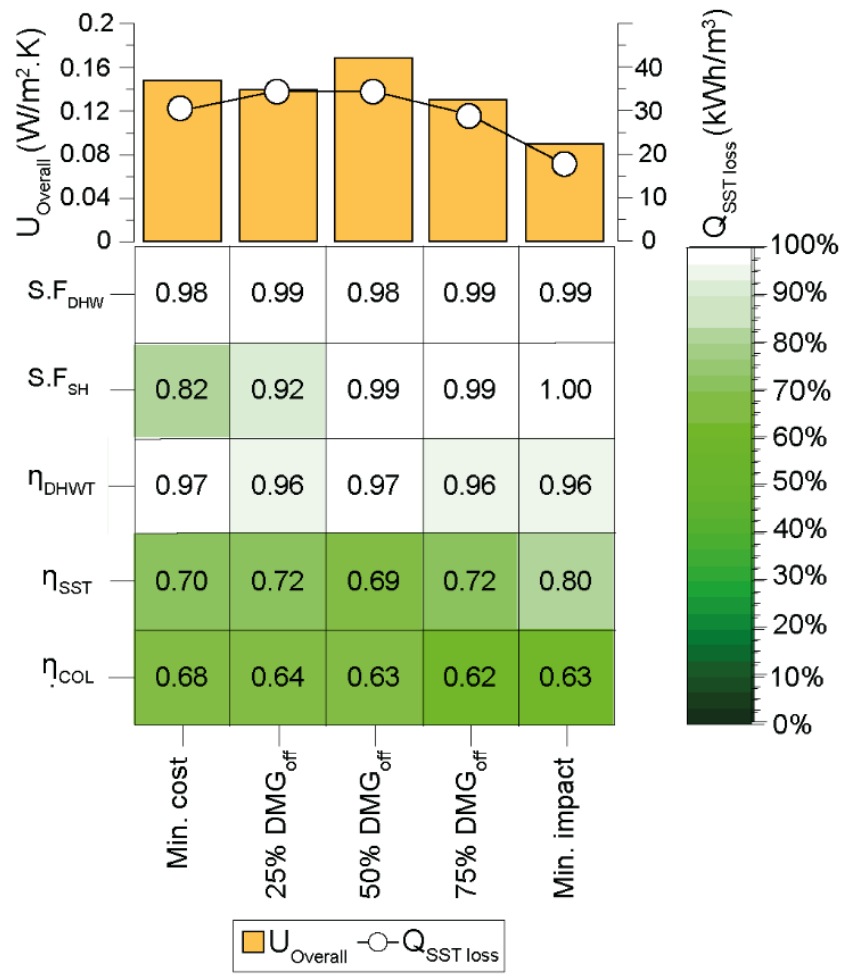

Fig. 6. The SST performance indicators 
Regarding the SST performance, the heat loss coefficient of the SST reduces from 0.15 in scenario 1 to $0.08 \mathrm{~W} / \mathrm{m}^{2}$. $\mathrm{K}$ in scenario 5. This reduction is reflected in the SST heat losses, which diminish gradually with increasing the environmental damage limits, and it reaches $18 \mathrm{kWh} / \mathrm{m}^{3}$ with an improvement of $45.2 \%$ compared to the scenario 1 . This improvement is emulated in the $\eta_{S S T}$ especially in the two extremes optimal scenarios (Min. cost and Min impact optimal solutions) where the $\eta_{S S T}$ is $70 \%$ and $80 \%$ in scenario 1 and 5 , respectively. In terms of the solar fraction for both $\mathrm{SH}$ and DHW distribution circuits, the solar fraction never falls below $80 \%$ for the $\mathrm{SH}$ circuit and below $98 \%$ for the DHW circuit.

\section{E. Comparison of the SDHS model to other real projects}

Since such solar community does not exist in Spain, this section compares the proposed simulation optimal solutions against other real SDHS projects. This section compares the proposed simulation optimal solutions against three real projects located in Germany based on nominal performance indicators. These projects include the Friedrichshafen, Hamburg, and Hannover plants, which were developed as a part of the "Solarthermie 2000" and "Solarthermie2000plus" project [42]. The Min. cost-optimal solution at a community size of 10 buildings is selected for comparison purposes. The assessment compares the heating demand, the solar collector area, the seasonal storage volume, and the solar fraction, as shown in Table II.

TABLE II. COMPARISON OF THE SDHS OPTIMAL DESIGN FDV SETTING FOR 10 BUILDINGS TO REAL SYSTEMS LOCATED IN FRIEDRICHSHAFEN [42], HAMBURG AND HANNOVER [43]

\begin{tabular}{|l|c|c|c|c|}
\hline & $\begin{array}{c}\text { SDHS, } \\
\text { Madrid } \\
\text { (Our } \\
\text { Results) }\end{array}$ & $\begin{array}{c}\text { Friedrichshafen, } \\
\text { Germany (1996) }\end{array}$ & $\begin{array}{c}\text { Hamburg, } \\
\text { Germany } \\
(\mathbf{1 9 9 6})\end{array}$ & $\begin{array}{c}\text { Hannover, } \\
\text { Germany } \\
(\mathbf{2 0 0 0 )}\end{array}$ \\
\hline $\begin{array}{l}\text { Heat } \\
\text { demand } \\
(\mathrm{MWh} / \mathrm{a})\end{array}$ & 1913.4 & 4106.1 & 1610 & 694 \\
\hline $\begin{array}{l}\mathrm{A}_{\mathrm{COL}} \\
\left(\mathrm{m}^{2} / \mathrm{MWh} / \mathrm{a}\right)\end{array}$ & 0.53 & 1.36 & 1.86 & 1.94 \\
\hline $\begin{array}{l}\mathrm{V}_{\mathrm{SST}} \\
\left(\mathrm{m}^{3} / \mathrm{MWh} / \mathrm{a}\right)\end{array}$ & 4.95 & 2.92 & 7.45 & 3.96 \\
\hline$S . F_{S H}$ & $82.1 \%$ & $33 \%$ & $49 \%$ & $39 \%$ \\
\hline
\end{tabular}

The renewable energy fraction has a favourable performance compared to the German plants, where a solar fraction of $82.1 \%$ is indicated for the low-performance solution (Min. cost-optimal solution). While the German plants could not exceed a solar fraction of $49 \%$ for the investigated projects, this vast difference between the German projects and the present study can partly attribute to the difference in the solar collector area to the heating demand ratio. However, including other design parameters regarding the renewable energy equipment in the SDHS can contribute to this improvement. Moreover, configurations in the present simulation study are optimized, so the results can reasonably be expected to be better than those from non-optimal real case studies. In terms of the SST volume, it is found that the project located in Hannover is reasonably comparable with our reference case, with some differences due to the climate conditions and including the SST construction materials in the optimization problem

\section{CONCLUSION}

This paper presents a framework to evaluate the feasibility of deploying the SDHS at a small urban community with tracing the technical failure of the seasonal TES. This is implemented through including the geometry and construction design parameters of the SST in the optimization problem. A summary for the analysis is the following:

- The calculated optimal solution demonstrates an improvement in the economic and environmental benefits for deploying SDHS instead of the natural gas boilers where the NPC is improved by $24.9 \%$ in the scenario 1 (Min-cost solution). While from the environmental impact point of view, the $R C P$ can be improved up to $87.1 \%$.

- The effect of including the SST material properties in the optimization problem is reflected in the SST performance where the $\eta_{S S T}$ goes up to is $80 \%$ in scenario 5 (Min-impact solution). Furthermore, in terms of the solar fraction for both $\mathrm{SH}$ and DHW distribution circuits, the solar fraction never falls below $80 \%$.

Overall, including the SST design parameters in the optimization of SDHS can have an environmentally viable alternative in Mediterranean climate regions that can lead to significant benefits. Furthermore, it can improve the thermal performance of the SDHS. However, the economic benefits especially for the small-sized community can be enhanced by including the governmental subsidies. It is therefore essential to define effective policies based on a longer-term view of the problem and the need to transition towards a more sustainable energy infrastructure.

\section{ACKNOWLEDGMENT}

The work is funded by the Spanish government RTI2018093849-B-C31 and RTI2018-093849-B-C33. The authors would like to thank the Catalan Government for the quality accreditation given to their research group (GREiA - 2017 SGR 1537, AGACAPE - 2017 SGR 1409). GREiA is a certified agent TECNIO in the category of technology developers from the Government of Catalonia. This work is partially supported by ICREA under the ICREA Academia programme. This work is partially funded by the Ministerio de Ciencia, Innovación y Universidades - Agencia Estatal de Investigación (AEI) (RED2018-102431-T). This project has received funding from the European Union's Horizon 2020 research and innovation programme under the Marie Skłodowska-Curie grant agreement No. 713679 and from the Universitat Rovira i Virgili (URV).

\section{REFERENCES}

[1] European Commission, 2016, Communication from the Commission to the European Parliament and the Council, Brussels. 
[2] European Energy Agency, 2017, Final Energy Consumption by Sector and Fuel, Denmark.

[3] Cabeza, L. F., Martorell, I., Miró, L., Fernández, A. I., and Barreneche, C., 2014, Introduction to Thermal Energy Storage (TES) Systems, Woodhead Publishing Limited.

[4] International Renewable Energy Agency (IRENA), 2013, The Energy Technology Systems Analysis Programme (ESTAP): Technology Brief E17.

[5] Reed, A. L., Novelli, A. P., Doran, K. L., Ge, S., Lu, N., and McCartney, J. S., 2018, "Solar District Heating with Underground Thermal Energy Storage: Pathways to Commercial Viability in North America," Renew. Energy, 126,pp. 1-13.

Dahash, A., Ochs, F., Janetti, M. B., and Streicher, W., 2019, "Advances in Seasonal Thermal Energy Storage for Solar District Heating Applications: A Critical Review on Large-Scale Hot-Water Tank and Pit Thermal Energy Storage Systems," Appl. Energy, 239(January), pp. 296-315.

[7] Rehman, H. ur, Hirvonen, J., and Sirén, K., 2018, "Influence of Technical Failures on the Performance of an Optimized CommunitySize Solar Heating System in Nordic Conditions," J. Clean. Prod., 175, pp. 624-640.

[8] Bauer, D., Marx, R., Nußbicker-Lux, J., Ochs, F., Heidemann, W., and Müller-Steinhagen, H., 2010, "German Central Solar Heating Plants with Seasonal Heat Storage," Sol. Energy, 84(4), pp. 612-623.

[9] Urbaneck, T., Oppelt, T., Platzer, B., Frey, H., Uhlig, U., Göschel, T., Zimmermann, D., and Rabe, D., 2015, "Solar District Heating in East Germany - Transformation in a Cogeneration Dominated City," Energy Procedia, 70, pp. 587-594.

[10] BINE Information Service, 2000, Solar-Assisted District Heating [Online].

[11] Federal Ministry for the Environment, N. C. and N. S., and (BMU), 2013, Storing Solar Energy in the Ground [Online].

[12] Nußbicker-Lux, J., Bauer, D., Marx, R., Heidemann, W., and MüllerSteinhagen, H., 2009, "Monitoring Results From German Central Solar Heating Plants With Seasonal Storage," Effstock, pp. 1-8.

[13] Sibbitt, B., McClenahan, D., Djebbar, R., Thornton, J., Wong, B., Carriere, J., and Kokko, J., 2012, "The Performance of a High Solar Fraction Seasonal Storage District Heating System - Five Years of Operation,” Energy Procedia, 30, pp. 856-865.

[14] Sibbit, B., McClenahan, D., Djebbar, R., and Paget, K., 2015, GroundBreaking Solar, Canada.

[15] Weissmann, C., Hong, T., and Graubner, C. A., 2017, "Analysis of Heating Load Diversity in German Residential Districts and Implications for the Application in District Heating Systems," Energy Build., 139, pp. 302-313.

[16] Hirvonen, J., ur Rehman, H., and Sirén, K., 2018, “Techno-Economic Optimization and Analysis of a High Latitude Solar District Heating System with Seasonal Storage, Considering Different Community Sizes," Sol. Energy, 162(January), pp. 472-488.

[17] Tulus, V., Abokersh, M. H., Cabeza, L. F., Vallès, M., Jiménez, L., and Boer, D., 2019, "Economic and Environmental Potential for Solar Assisted Central Heating Plants in the EU Residential Sector: Contribution to the 2030 Climate and Energy EU Agenda," Appl. Energy.

[18] Tulus, V., Boer, D., Cabeza, L. F., Jiménez, L., and GuillénGosálbez, G., 2016, "Enhanced Thermal Energy Supply via Central Solar Heating Plants with Seasonal Storage: A Multi-Objective Optimization Approach," Appl. Energy, 181, pp. 549-561.
[19] De Guadalfajara, M., Lozano, M. A., and Serra, L. M., 2012, "Evaluation of the Potential of Large Solar Heating Plants in Spain," Energy Procedia, 30, pp. 839-848.

[20] Duffie, J.A., Beckman, W. A., 2006, Solar Engineering of Thermal Processes, John Wiley \& Sons, Inc.

[21] Chung, M., Park, J., and Yoon, H., 1998, "SIMULATION OF A CENTRAL SOLAR HEATING SYSTEM WITH SEASONAL STORAGE IN KOREA,” Sol. Energy, 64, pp. 163-178.

[22] Allouhi, A., Agrouaz, Y., Benzakour Amine, M., Rehman, S., Buker, M. S., Kousksou, T., Jamil, A., and Benbassou, A., 2017, "Design Optimization of a Multi-Temperature Solar Thermal Heating System for an Industrial Process," Appl. Energy, 206(August), pp. 382-392.

[23] Hobbi, A., and Siddiqui, K., 2009, "Optimal Design of a Forced Circulation Solar Water Heating System for a Residential Unit in Cold Climate Using TRNSYS," Sol. Energy, 83(5), pp. 700-714.

[24] Hui, L., Edem, N. T. K., Nolwenn, L. P., and Lingai, L., 2011, "Evaluation of a Seasonal Storage System of Solar Energy for House Heating Using Different Absorption Couples," Energy Convers. Manag., 52(6), pp. 2427-2436.

[25] Hang, Y., Qu, M., and Ukkusuri, S., 2011, "Optimizing the Design of a Solar Cooling System Using Central Composite Design Techniques," Energy Build., 43, pp. 988-994.

[26] Allouhi, A., Agrouaz, Y., Benzakour Amine, M., Rehman, S., Buker, M. S., Kousksou, T., Jamil, A., and Benbassou, A., 2017, "Design Optimization of a Multi-Temperature Solar Thermal Heating System for an Industrial Process," Appl. Energy, 206(November), pp. 382392.

Kalogirou, S. A., 2009, Solar Energy Engineering: Processes and Systems, Academic Press.

Pavičević, M., Novosel, T., Pukšec, T., and Duić, N., 2017, "Hourly Optimization and Sizing of District Heating Systems Considering Building Refurbishment - Case Study for the City of Zagreb," Energy, 137, pp. 1264-1276.

[29] Gluch, P., and Baumann, H., 2004, "The Life Cycle Costing (LCC) Approach: A Conceptual Discussion of Its Usefulness for Environmental Decision-Making," Build. Environ., 39(5), pp. 571580 .

[30] Guillén-Gosálbez, G., Caballero, J. A., and Jiménez, L., 2008, "Application of Life Cycle Assessment to the Structural Optimization of Process Flowsheets,” Ind. Eng. Chem. Res., 47(3), pp. 777-789.

[31] Nemerow, N. L., Agardy, F. J., Sullivan, P., and Salvato, J. A., 2009, ENVIRONMENTAL ENGINEERING: Environmental Health and Safety for Municipal Infrastructure, Land Use and Planning, and Industry, John Wiley \& Sons, Inc.

ISO/TC 207/SC 5, 2006, "ISO 14040:2006 Environmental Management — Life Cycle Assessment — Principles and Framework."

[33] International Organization for Standardization (ISO), 1997, ISO 14041: Environmental Management - Life Cycle Assessment: Goal and Scope Definition and Inventory Analysis.

[34] International Organization for Standardization (ISO), 2000, ISO 14042:Environmental Management - Life Cycle Assessment - Life Cycle Impact.

[35] Welsch, B., Göllner-Völker, L., Schulte, D. O., Bär, K., Sass, I., and Schebek, L., 2018, "Environmental and Economic Assessment of Borehole Thermal Energy Storage in District Heating Systems," Appl. Energy, 216(January), pp. 73-90. 
[36] Ecoinvent, 2017, "Eco Invent" [Online]. Available: https://www.ecoinvent.org/home.html. [Accessed: 12-Mar-2018].

[37] JRC European commission (JRC-IES), 2011, ILCD Handbook: Recommendations for Life Cycle Impact Assessment in the European Context, Office of the European Union, Luxemburg.

[38] Gonzalez-Garay, A., and Guillen-Gosalbez, G., 2018, "SUSCAPE: A Framework for the Optimal Design of SUStainable ChemicAl ProcEsses Incorporating Data Envelopment Analysis," Chem. Eng. Res. Des., 137, pp. 246-264.

[39] K. Deb, A. Pratap, S. A. and T. M., 2002, "Fast and Elitist Multiobjective Genetic Algorithm: NSGA-II," IEEE Trans. Evol. Comput., 6(2), pp. 182-197.

[40] Hassam ur Rehman; Janne Hirvonen; Kai Sirén, 2018, "Performance Comparison between Optimized Design of a Centralized and SemiDecentralized Community Size Solar District Heating System,"
Appl. Energy, 229(August), pp. 1072-1094.

[41] Alajmi, A., and Wright, J., 2014, "Selecting the Most Efficient Genetic Algorithm Sets in Solving Unconstrained Building Optimization Problem,” Int. J. Sustain. Built Environ., 3(1), pp. 1826.

[42] Bauer, D., Marx, R., and Nußbicker-Lux, J., 2010, "German Central Solar Heating Plants with Seasonal Heat Storage," Sol. Energy, 84(4), pp. 612-623.

[43] Schmidt, T., Mangold, D., and Müller-Steinhagen, H., 2004, "Central Solar Heating Plants with Seasonal Storage in Germany," Sol. Energy, 76(1-3), pp. 165-174. 